chlorides were entirely absent it would not act (supposing albumen be also present), and if they were only sparingly present it might or might not act according to the amount of chlorides. A theoretical point also suggests itself. It is known that if albumen be precipitated by mercuric chloride the precipitate can be readily dissolved by the addition of a strong solution of sodium chloride, and if sodium chloride be previously added to a solution of albumen mercuric chloride very often fails to cause any precipitate. I say very often, because much depends on the strength of the solutions of mercuric chloride and sodium chloride. This action of a combination of the two chlorides on albumen has been taken advantage of in preparing solutions for use in antiseptic surgery, a double chloride to a large extent hindering coagulation of the proteids issuing from wounds and sores. Tartaric acid also hinders, to a large extent, any great precipitate of albuminous substances when united with mercury, and it, too, was at one time employed as an adjunct to mercuric chloride solution in surgical dressings. Might we not then bave a concentrated urine in which chlorides were in great excess acting on any contained albumen, and rendering it highly soluble and non-precipitable by mercuric chloride? I think that such is possible.

From what has just been said the loopholes for error, which are opened first by adding anything of the nature of tartaric acid to mercuric chloride, and secondly by the presence of a large amount of a soluble chloride with albumen in the precipitation of albumen, will be at once apparent. So much reliance did I at one time place on the power of sodium chloride to dis solve precipitated albumen that I worked a good deal in trying to obtain a volumetric test for albumen, first by precipitating by mercuric chloride and then reading off the quantity of a standard solution of sodium chloride necessary to dissolve the precipitate. Constant results were not obtained and the work was abandoned for the time being. This again shows how fallacies may occur when we have to reckon with sodium chloride. The fact is, too little is yet known about albumen, and what we call albumen may be really an albuminate of, say, calcium. The action of mercuric salts goes a long way to show that it is something of this kind, as, for example, $\mathrm{CaAlb}+\mathrm{HgCl}_{2}=\mathrm{HgAlb}+\mathrm{CaCl}_{2}$. However, the mercuric albuminate is evidently not a constant compound from the fact that the same quantity of sodium chloride does not always dissolve the precipitate as shown above. Lastly, it is doubtful whether all the tests put together are worth the old nitric acid test; the white characteristic cloud which it forms with albumen is well known and can hardly be mistaken by anyone. Picric acid, trichloracetic acid, and others are delicatein fact, too delicate; besides, they possess other disadvantages: the first must be in concentrated aqueous solution, the second is rather expensive, and both are rare articles, while nitric acid is always handy; and if the strong acid be employed and care be taken to have two layers (one of acid at the bottom and one of urine above it), then the test leaves nothing to be desired, the urine having previously been tested by heating a separate portion.

Meanwood-road, Leeds.

\section{Clinitall thotes:}

\section{MEDICAL, SURGICAL, OBSTETRICAL, AND THERAPEUTICAL.}

\section{CASE OF CALCULUS IMPACTED IN THE MALE URETHRA, AND REMOVAL BY CRUSHING. \\ By E. Mansel Sympson, M.D., B.C. Cantab., M.R.C.S. EnG., \\ SURGEON TO THE LINCOLN COUNTY HOSPITAL.}

ON Nor. 22nd, 1893, I was consulted by a young man aged twenty-eight who was suffering from impacted calculus in the penile urethra. The stone was readily felt externally, was about the size of the stone of a French plum and somewhat of the same shape, and was situated about three inches from the meatus. It had come down into the urethra a few hours previously, and was causing pain and difficulty of micturition, only a drop being occasionally passed. He had had a similar attack before when he was in Australia. I first tried to get the urethra distended all round the stone by compressing the meatus and getting him to strain, but he could do very little to help. Then I tried to manipulate it with my fingers, but without success. I next passed a pair of narrow longbladed forceps down to the stone, to try to grip it, but the walls of the urethra kept squeezing into the teeth of the forceps. Upon this I tried distending the distal portion of the urethra with warm oil, and then, as the stone would not move outwards, I passed a catheter and made an attempt (which gave the patient so much pain that I was obliged to desist) to push it back into the bladder. He would not have an anæsthetic and I could not persuade him to go into the hospital, so, encouraged by the phosphatic débris which had come away on the catheter and forceps and the circumstance that an Australian surgeon had crushed the former stone also in the urethra, I commenced to crunch the stone away, holding it firmly between the left finger and thumb and opening and shutting the forceps quickly, but for a very short interval each time. I tried several pairs of forceps, butthe best seemed to be an ordinary pair of Spencer Wells' artery forceps, as the bulge about the hinge kept the walls of the urethra from getting between the jawe. Purposely I did not use any form of local anæsthesia, so that the patient could guide me if any part of the mucous membrane was nipped. After about two hours of this work, which had to be extremely gentle and gradual, most of the stone had disappeared and I was able to introduce a long pair of forceps, grip and smash the remainder and extract the fragments ; the core was uric acid with a great bulk of phosphatic accretions The patient bore the operation wonderfully well, micturated satisfactorily within a few hours after it, and more than two months after the operation was perfectly sound as far as the urethra was concerned. The after-treatment consisted in keeping him in bed for a day, putting him on citrate of potash and infusion of bearberry and recommending him to take plenty of salt with his food.

James-street, Lincoln.

THE TREATMENT OF INTUSSUSCEPTION BY GENERATING CARBON DIOXIDE WITHIN THE BOWEL.

Bx John Thomas Creswick Williams, M.R.C.S. Eng., L.R.C.P. LOND., L.S.A.

ON Dec. 21st, 1890, I was called to see a boy aged eight months. The mother stated that the child had passed a restless night, that he suddenly started out crying, and at times was rolling with pain. Upon examination he was found to be weil nourished, and appeared to be healthy and well developed. He had suffered from slight diarrhcea during the week and for the previous twenty-four hours had had violent straining and had passed slimy mucous stools tinged with blood. When put to the breast he soon stopped sucking and immediately vomited. Cow's milk with water and all other nourishment were likewise quickly rejected. The vomit had an offensive smell, but was not stercoraceous. The abdomen was somewhat distended. Midway between the umbilicus and the crest of the ilium on the left side a swelling was. visible; it was doughy to the feel, dull upon percussion, and sausage-shaped, its long axis lying parallel to the fold of the groin. There was tenderness upon pressure in the vicinity of the swelling. I tried all the prescribed methods of treatment, including kneading, inversion combined with manipulation, injection of warm water, and the insufflation of air, and all proved to be of no avail. I suggested laparotomy, but the parent would not consent to any cutting operation. It occurred to me that if it were only possible to generate gas within the intestine and prevent its escape through the anus, the gas, passing upwards, might reduce the intussusception. I therefore procured two basins, each containing about half a pint of warm water. In one I dissolved a drachm and a half of citric acid, and in the other two drachms of bicarbonate of soda. A flexible catheter was attached to a Higginson's enema and passed into the bowel to the extent of nine inches, whereupon I injected first the acid and afterwards (slowly) the alkaline solution. The result was the generation of carbonic acid gas, which was perceptibie by a distension of the abdomen. The catheter was quickly withdrawn, and the nates were held firmly together for two or three minutes, in order to prevent the escape of the gas. During this time the chilu made a strong effort to dispel it. After a few minutes the abdominal swelling above described had entirely disappeared. 
The child ceased to vomit, and in two days passed a natural stool, recovery being quite complete.

Remarks. - It could easily be ascertained what volume of earbonic acid gas is generated by the combination of various acids and carbonates, and it would be of value to know what amonnt of gas could with safety be rapidly generated within the bowel ; for, as these cases call for prompt treatment, it might be necessary in an emergency to use such domestic remedies as chalk, or washing soda with vinegar, or a Seidlitz powder. Of course this treatment is not free from danger, and in a case which is far advanced, and where gangrene has set in, it might cause rupture of the gut; but if the case is taken early, all other means having failed, and laparotomy is not allowed, I believe there is full justification in resorting to this mode of treatment.

Whitland, South Wales.

\section{A dirtor}

\section{HOSPITAL PRACTICE, BRITISH AND FOREIGN.}

Nulla autem est alia pro certo noscendi via, nisi quamplurimas et mor borum et dissectionum historias, tum aliorum tum proprias collectas habere, et inter se comparare.-MoRGAGNI De Sed. et Caus. Mforb. lib. iv. Procemium.

\section{METROPOLITAN HOSPITAL.}

STRANGULATION OF THE TESTICLE WITHOUT ROTATION; REMARKS.

(Under the care of Mr. PAGET.)

We have published in THE LANCET a complete list of cases in which strangulation of the testis has been recognised to follow twisting of the cord. In most of them the testis was mandescended-that is, retained in the inguinal canal-and ill-developed. In Mr. Paget's case the testis appears to have been suddenly forced from a position within the internal ring to one outside the canal. Although the testis was necessarily small, when it had been forced outside the external ring, two causes would act more especially in producing strangulation: the unaccustomed stretching of the cord, and the rigidity of the opening through which the testis had escaped. A case of somewhat similar character has been recorded by Mr. Jacobson, in which strangulation of a testis, which suddenly descended into the groin, but not through the external ring, took place and the testis was removed by operation.

The patient was sixteen years of age. The right testicle had never descended into the scrotum, nor had it been felt in the inguinal canal. About four years before, the boy said, it came down once, producing pain; but after some days it returned into the body. On the evening of Nov. 25th, while in the act of lifting a heavy weight, the testicle suddenly descended into the scrotum, and he experienced acute pain. The following morning he vomited; the bowels had not been opened and the pain still conwinued. On the $27 \mathrm{th}$ he was admitted into the Metropolitan Hospital. The patient was examined on the 28th. Just outside and below the external abdominal ring and close under the skin there was a firm, tense, rounded, irreducible swelling, about an inch in diameter; it was freely movable and was not sensitive to pressure. The skin over the lower part of it was hot and red. Between it and the exbernal abdominal ring, when gentle pressure was made, something was felt to slip away from the touch, like a small lax hernia. He was slightly feverish; the bowels had not acted, even after an enema. The vomiting had stopped. Mr. Paget cut down and first came upon a firm, dark blood-clot, about three-quarters of an inch in diameter, lying in a thin envelope of areolar tissue. This lay to the inner side of a sac, at the bottom of wbich was the testicle, of a dull purplish black, full of effused blood, and almost gangrenous. There was no twist of the cord. The sac had a very narrowed neck, only just admitting a probe. The testicle was removed, but not the sac. The bowels were not moved till the fourth day and after the administration of calomel. At this time he was slightly jaundiced for a day or two. There was some sloughing of the tissues at the upper end of the wound, so it was laid open and left to granulate, and there was no further trouble.

Remarks by Mr. PAGET. - The testicle on section was found to be soddened with blood and wholly disorganised, but there was no putrefactive smell from it. The round blood-clot that lay just outside it, enclosed in a thin film of areolar tissue, so closely resembled a knuckle of strangulated bowel that very careful dissection was necessary. Several cases have lately been published of strangulation from twisting of the cord, but in this case it was not twisted.

\section{BROMLEY COTTAGE HOSPITAL, KENT.}

CASE OF EXCISTON OF THE CACUM FOR MALIGNANT GROWTH ; INTESTINAL ANASTOMOSIS BY USE OF SENN'S PLATES ; RECOVERY.

(Under the care of Dr. HerberT J. ILOTT.)

THE number of cases operated on for the removal of malignant disease of the cæcum in this country is a limited one, and therefore the account of the following case will be interesting. The operation described is one which is called for by malignant growth in this region-namely, complete removal of the disease and the immediate reestablishment of the intestinal canal. The prognoses in operations for malignant disease situated in this part of the bowel are not unfavourable ; for, as pointed out by Matlakowski, carcinoma of the cæcum is not rarely a very chronio condition that may exist for years, only giving rise to symptoms of obstruction and the presence of a tumour. It will be noted that the longitudinal incisions which were made for the re-establishment of the connexion between the ileum and the colon were only one inch in length. It is important that the future progress of the case should be reported, for to many these incisions will appear to be rather small in view of possible contraction. In an account of a case, however, recorded by Dr. Kammerer, no contraction had taken place in a similarly formed opening two inches and a half wide four months after the date of the operation.

A married woman fifty years of age, who had borne eleven children and had good general health, was admitted to the Bromley Cottage Hospital under the care of Dr. Ilott on June 26th, 1893. She had a somewhat pallid complexion and had lost flesh and strength of late. Her state of ill-health had developed during the past six months, when she had begun to experience pain in the right side of the abdomen, back ache, and a feeling of pressure in the hypogastrium. About four months ago she felt a lump above the right groin which steadily increased in size. There had been irregularity in the action of the bowels, a state of constipation alternating with diarrhœa. Shortly after her admission into the hospital she had relaxed motions containing blood and mucus. On examination a tumour was discovered in the right inguinal region, in the position of the cæcum. It was nodular in feel, rounded, and freely movable, especially in a direction inwards. The tumour was tender when handled. It could not be felt by the vagina or rectum. The uterus was retroflexed and the cervix widened; the inguinal glands on both sides were somewhat enlarged, and on the right side one gland was more so than the rest. On July 1st she was seen in consultation by Mr. Walsham, who concurred with Dr. Ilott in the view that the tumour was probably a cancerous growth involving the cæcum and that an attempt at its removal by operation should be at once made. The patient, having been previously prepared, was then brough into the operating-room, and Dr. Ilott opened the abdomen by an incision about four inches long in the right semilunar line over the tumour, the line of the incision being slightly curved inwards. On opening the abdominal cavity the growth was seen to be covered by the omentum. This was raised and pushed inwards, and the tumour was then seen to be, as was thought, a $n$ alirnant tumour of the cæcum. There was an enlarged gland close to the cæcum. The patient's state under anæsthesia being good, it was decided under Mr. Walsham's advice, to proceed with the operation After the affected part of the bowel had been isolated by sponges wrung out of warm carbolic lotion packed behind it, the tumour was lifted out of the wound and freed by cutting away the mesocolon with scissors, any bleeding vessels being secured and divided by ligature with fine carbolised silk. A hole being made in the mesentery on either side of the tumour, opposite a part of healthy 